\title{
New Materials for SLS: The Use of Antistatic and Flow Agents
}

\author{
Matthias Michael Lexow and Dietmar Drummer \\ Institute of Polymer Technology, Friedrich-Alexander-University Erlangen-Nürnberg, Am Weichselgarten 9, 91058 Erlangen, Germany
}

Correspondence should be addressed to Matthias Michael Lexow; lexow@lkt.uni-erlangen.de

Received 15 March 2016; Revised 10 May 2016; Accepted 17 May 2016

Academic Editor: Wei Hsing Tuan

Copyright (C) 2016 M. M. Lexow and D. Drummer. This is an open access article distributed under the Creative Commons Attribution License, which permits unrestricted use, distribution, and reproduction in any medium, provided the original work is properly cited.

\begin{abstract}
Selective laser sintering (SLS) is a process based on the principle of a locally confined energy input by a laser into a powder bed, producing highly complex parts without the use of moulds or any other tools. In order to ensure good results for the processing behaviour of a new material, the powder must perform well during the phase of feeding the material into the process chamber which majorly influences the quality of the spread of the powder into the part bed and thus the mechanical performance of the final parts. In the present study, the principle of modification of fine powders with flow agents is applied aiming to enable the use of powders for SLS which are otherwise unsuitable due to poor flowability. In addition, the influence of antistatic agent on the powder flow and processing behaviour is discussed. The additives are found to strongly improve the flow behaviour at already very small contents and thus allow for processing of the composite material. The development of determining factors shares insight into the mechanisms of dry particle coating and its implementation into a growing market of material development.
\end{abstract}

\section{Introduction}

An increasing demand for geometrical complexity and the trend to shorter life-cycles of plastic products lead to rising expectations concerning the flexibility and efficiency of production processes. With almost unlimited freedom of shaping, additive manufacturing (AM) technologies offer innovative perspectives for the realisation of complex designs of engineering parts. In the past, the manufacturing of prototypes was the most typical application of AM, aiding in avoiding mistakes during product development and shortening the time-to-market. Since then, increasing use of direct manufacturing of parts for end-user applications, for example, dental technology and hearing aids, was established [1-3]. Following this trend, prospects of further establishment of AM grow as increasing technological advancement is achieved. While new possibilities for the AM of polymer parts for the medical, aerospace, and automotive industries are revealed, an increasing share of all additively manufactured parts is used as functional components [2]. In particular, with respect to the possible mechanical properties, selective laser sintering (SLS) offers a vast potential for possible applications in resourceefficient serial manufacturing of plastic parts $[3,4]$.
The SLS process is based on the principle of a locally confined energy input by a laser into a powder part bed, producing highly complex parts layer-by-layer without the use of moulds or any other tools for shaping the geometry. Figure 1 shows a schematic of the SLS setup, which basically comprises the part bed on a movable platform, a $\mathrm{CO}_{2}$ laser, and a powder feed system combined with a coating mechanism, typically a roller or a blade. Before starting the process, a threedimensional CAD model is virtually sliced into layers of a thickness of typically $0.1 \mathrm{~mm}$. The data of each layer contains the geometrical information along which the laser scans the respective cross section of the part. Following the exposure of a layer, the part bed is retracted by the set layer thickness. The resulting free volume is then filled with new powder from the material feed by the coating mechanism. Before the next exposure phase is initiated, the surface of the part bed is reheated to a defined temperature close to the melting point well above the crystallisation temperature of the polymer material in order to avoid uncontrolled crystallisation and thus warping or deformation of the unfinished parts. The three process steps are repeated until the whole part is completed in this layerwise additive manner. To finish the build, the part chamber is slowly cooled down in order to 


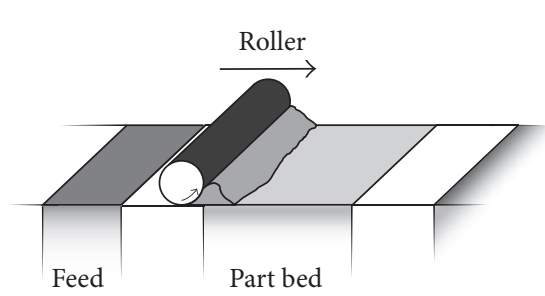

Powder deposition

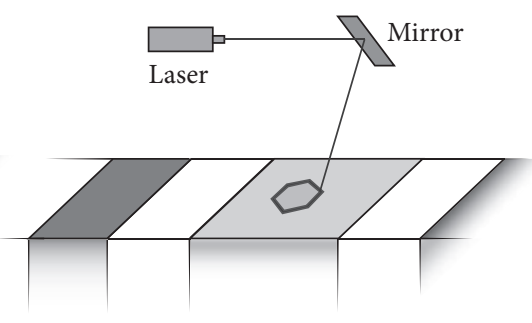

Geometry exposure

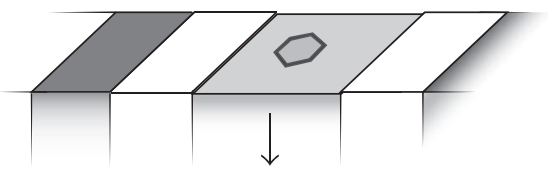

Retraction of part bed

FIGURE 1: Schematic of the SLS process.

allow solidification of the manufactured parts before they can be extracted from the surrounding powder [5].

Across all techniques of additive manufacturing, the limited choice of different materials is considered a major restricting factor $[1,2,6]$. The dominant market position of PA 12 for SLS is generally attributed to a small range of alternative materials and inferior properties especially for technical applications $[7,8]$. In the past, there was much potential for improvement on PA 12 based SLS materials [9] with much effort put into research on ageing and regeneration strategies $[10,11]$ as well as the modification with fillers with an eye on new and specialised fields of applications [1,12-14]. At present, however, fewer possibilities for further improvement of PA 12 part quality are left to material development. However, as recently great progress is made on the basic understanding on the very foundations of the material behaviour during the sintering subprocesses [3, 15-19], new chances arise for specific development of new materials based on various approaches such as addition of fillers or additives [12-14] or copolymerisation and blending with other polymers $[1,20]$. This results in an increased motivation for research on other polymers or polymer combinations, respectively. The introduction of new material choices for laser sintering to the market is believed to inspire the adaption of SLS to new applications and further establishing additive manufacturing technologies for serial manufacturing $[1,2]$. Many approaches for new materials are based on polymer powders from cryogenic grinding because of the possibility to adjust the composition in a foregoing compounding step. These powders are commonly defined by a rough and irregular shape due to the brittle fraction at low temperatures during the grinding process. Along with the dimensional characteristics of the ground powder, poor flowability and a low bulk density are generally observed which results in a bad processing behaviour especially considering the powder coating phase during the generation of a new layer in the SLS process $[8,21]$. This step is of paramount importance for the resulting part density and thus the mechanical properties of the final parts [22]. In order to improve the flow properties inorganic powder additives, the so-called flow agents, with particle sizes typically below $1 \mu \mathrm{m}$, can be added. According to the existing models, these flow agents, typically consisting of fumed silica, glassy oxides, metallic stearates, or fluoroplastics [23, 24], adsorb onto the surface of the larger powder particles; compare with Figure 2.

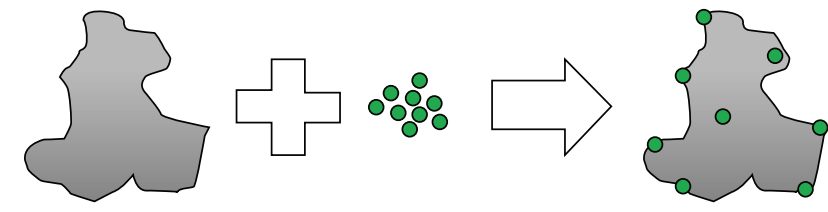

FIgURE 2: Schematic of the principle of dry particle coating. During mixing, agglomerates of the flow agent are dispersed and adsorbed onto the surface of the much larger polymer particles.

By reducing the contact area between the large particles, the interparticular adhesion decreases, which enables less restricted movement of the particles relative to one another $[25,26]$. As a consequence, a more smooth powder flow can be observed. Popular applications of flow agents concern pharmaceutical products, the food industry, for example, spices, and other finely powdered bulk goods [27].

Plastics are typically electrically insulating materials. Antistatic agents find use in plastics to eliminate static charge which can facilitate several aspects of handling and processing [28]. In polyolefins ethoxylated alkylamines and fatty acid esters often find use with typical contents of 0.05 to $1.5 \%$, but more commonly below $0.5 \%$, however, depending strongly on the total formulation and the type of application for the material $[28,29]$. These types of antistatic agents are partly polar and partly nonpolar. The polar group is chosen for its affinity to water. Due to the only partial compatibility with the polyolefin, the antistatic agent slowly migrates to the surface and forms a moist, electrically conductive surface layer with adsorbed water which allows surface charge to drain [28].

In the context of the present study, the improvement of the flow properties is demonstrated on the example of commercially available granular polypropylene (PP). Fiedler et al. already discussed the general processability for different PP grades, however, stating the need for adequate modification of the materials in order to reach satisfying results for the resulting part quality [31]. By the formation of composite particles, it is shown how the flow properties of polymer powders from cryogenic grinding can be modified in order to enable the use of previously unsuitable powders for SLS. Secondly, the influence of antistatic agent on the powder flow and processing behaviour will be discussed. 


\section{Experimental}

2.1. Materials. For the experiments, granular materials of commercial, heterophasic propylene-ethylene copolymer types Moplen EP548V and Moplen EP600V, LyondellBasell Industries N.V., are used. The polymer grades with high melt fluidity are originally designed for thin-walled applications in injection moulding with a high stiffness and good impact resistance. Both types have a density of $0.9 \mathrm{~g} / \mathrm{cm}^{3}$ and are selected because of a suitable thermal behaviour with a large difference between melting point $T_{m}$ and crystallisation peak temperature $T_{c}$. The two Moplen types share the same base polymer. However, the type EP548V contains the antistatic agent glycerol monostearate and nucleating agent. While the content of antistatic agent is considered to potentially improve the flow behaviour due to decreased surface charging, the influence of nucleating agent on the process stability during SLS also has to be investigated.

After grinding, the polymer powders are modified through addition of the flow agent Aerosil R8200, Evonik Industries AG, which consists of very fine particles of hydrophobic fumed silica with diameters in the nanometre range. It is selected for the present study due to its nonpolar nature, which provides good compatibility with the also nonpolar PP.

2.2. Preparation of the Polymer Powders. The commercial polymer granules for injection moulding are transformed into a powder by means of cryogenic grinding. A high performance pin mill C160, Hosokawa Alpine AG, is applied with liquid nitrogen as coolant. The ground powder is sieved with a mesh width of $200 \mu \mathrm{m}$ in order to remove coarse particles. As reported by Shi et al. [32], the particle size affects both the precision and the density of the resulting SLS parts. The influence of different particle sizes and size distributions, respectively, is, however, not the topic of this study.

The particles of the ground PP are modified by mixing with $0.1 \mathrm{wt} \%$ of the inorganic flow agent Aerosil R8200. Ruppel [25] and Blümel [33] showed on the example of various combinations of powders and flow agents that the parameters mixing time, type of mixer, and energy input during mixing can have a strong influence on the quality of the formed composite particles. In the present study, the polymer powder and flow agent are mixed at static conditions in a universal mixer Standmischer MP, Somakon Verfahrenstechnik UG, Lünen, for $20 \mathrm{~min}$ at $250 \mathrm{rpm}$.

2.3. Characterisation and Analysis. Differential scanning calorimetry (DSC) is run according to ISO 11357 on a TA Instruments Q 1000 TMDSC. Heating and cooling rates are set to $10 \mathrm{~K} / \mathrm{min}$. The weight of the DSC samples is between 3 and $5 \mathrm{mg}$.

The numerical particle size distribution (PSD) of the ground polymer powders is determined via automated static image analysis using a Malvern Instruments Morphologi G3.

The powder samples are also examined using a scanning electron microscope (SEM) Zeiss Ultra Plus with a field emission source and an acceleration of $2 \mathrm{kV}$. For the topographic imaging of the particles, secondary electrons are detected.
Prior to the examination in the SEM, the powder samples are sputter-coated with platinum/gold.

The respective flowability values of the raw and modified powder samples are measured with the funnel method according to ISO 6186. The flow times are determined by running samples of $150 \mathrm{~g}( \pm 1 \mathrm{~g})$ of polymer powder at diameters of $25 \mathrm{~mm}, 15 \mathrm{~mm}$, and $10 \mathrm{~mm}$ for the opening at the bottom of the funnel. The bulk density of the powder is determined according to ISO 60. The powder flow characteristics are analysed in order to estimate whether a homogeneous powder layer can be realised during the SLS coating phase. An increase in the bulk density is considered to decrease the porosity and thus to directly improve the mechanical properties of the resulting laser sintered parts.

2.4. Laser Sintering Trials. Both the unmodified and the modified powder materials are characterised within the SLS process. As a first measure of the general process behaviour of the different powders, the spreading of the powder during the coating phase and the quality of the resulting part bed surface are closely observed. The evaluation of a new material has to include also a parameter study of the SLS process. In this study, a commercial SLS system DTM Sinterstation 2000, 3D Systems, is used. The processing behaviour and resulting part properties in SLS not only are material dependent but also vary strongly with processing conditions [34]. Values for laser power and scan speed are varied throughout the experiments in order to ascertain stable process conditions. The limits of the variation for the respective parameters are given in Table 1. In order to increase the process stability, a scan count of 2 is applied. The choice for a double scan count is based on previous findings of Goodridge et al. [35]. During laser sintering studies on polyethylene, they noted that using a double scan count the energy is delivered in a more gradual manner into each layer which causes a less drastic reaction of the material. As a result, a greater definition of the parts and significantly less shrinkage and curling, respectively, are observed. While the double scan count is thus able to considerably increase the process stability, it is also important to note that the exposure of each cross section takes twice as long as it normally would. A simple slice fill strategy in uniaxial direction without the additional application of an outline scan is used for the manufacturing of the test specimens in order to selectively determine the influence of the variation of the energy input on the resulting part properties. The roller speed is kept constant at $177 \mathrm{~mm} / \mathrm{s}$, as well as the hatch distance, that is, the distance between two adjacent scan traces, of $0.15 \mathrm{~mm}$. The layer thickness is set to $0.15 \mathrm{~mm}$ due to a significant content of particles larger than $100 \mu \mathrm{m}$.

Before starting the variation for the laser scanning parameters, a suitable part bed temperature is determined. From previous experiments with other PP types, a temperature between $150^{\circ} \mathrm{C}$ and $160^{\circ} \mathrm{C}$ is estimated for the Moplen EP600V powder. The optimal setting is then determined at $156^{\circ} \mathrm{C}$ as a compromise between uniform powder flow, a resulting smooth part bed, and the suppression of curling. Subsequently, rectangular samples of $(40 \mathrm{~mm} \times 10 \mathrm{~mm} \times$ $4 \mathrm{~mm}$ ) are fabricated upon variation of the laser parameters power and scan speed. After inspection of the part quality, 
TABLE 1: Overview of SLS process parameters and their variation limits.

\begin{tabular}{lcccc}
\hline $\begin{array}{l}\text { Feed temp. } \\
{\left[{ }^{\circ} \mathrm{C}\right]}\end{array}$ & $\begin{array}{c}\text { Part bed } \\
\text { temp. } \\
{\left[{ }^{\circ} \mathrm{C}\right]}\end{array}$ & $\begin{array}{c}\text { Laser } \\
\text { power } \\
{[\mathrm{W}]}\end{array}$ & $\begin{array}{c}\text { Scan } \\
\text { speed } \\
{[\mathrm{mm} / \mathrm{s}]}\end{array}$ & $\begin{array}{c}\text { Energy density } \\
{\left[\mathrm{J} / \mathrm{mm}^{2}\right]^{*}}\end{array}$ \\
\hline $80-90$ & $155-157$ & $3.5-12$ & $\begin{array}{c}1750- \\
3500\end{array}$ & $0.013-0.057$ \\
\hline
\end{tabular}

${ }^{*}$ Calculated from Nelson's definition of the energy density [30], also considering the double scan count.

scan speeds between $2800 \mathrm{~mm} / \mathrm{s}$ and $3500 \mathrm{~mm} / \mathrm{s}$ and laser powers in the range of $6.4 \mathrm{~W}$ and $10 \mathrm{~W}$ are selected for the manufacturing of specimens for tensile tests.

2.5. Part Characterisation. The mechanical properties of manufactured CAMPUS tensile bars (ISO 3167, type A) are determined in tensile tests according to ISO 527-1 on a Zwick testing machine type 1465 . The test speed is $1 \mathrm{~mm} / \mathrm{min}$ for the determination of Young's modulus and $5 \mathrm{~mm} / \mathrm{min}$ for tensile strength and elongation at break. The dimensional accuracy of the parts is determined with a calliper at different positions along the tensile bars. Additionally, microscopic examination of the inner structure of the specimens is done on thin layers with a thickness of $10 \mu \mathrm{m}$. The samples are cut using a rotary microtome type HM350 of MICROM. The images are recorded on an Axioplan microscope of the Carl Zeiss Jena AG in polarisation optical mode. The microscopic analysis is repeated at different positions within the sample to reduce the probability of an incorrect interpretation due to the possibility of a local confinement of certain part properties.

\section{Results and Discussion}

3.1. Characterisation of the Powder. The DSC measurements of the PP granules and the cryogenically ground powder are presented in Figure 3. Both materials, Moplen EP600V and EP548V, exhibit a similar melting behaviour with a common peak maximum at $165^{\circ} \mathrm{C}$. This is not surprising as the base polymer is the same. The crystallisation behaviour of EP548V, however, seems to be affected by the content of nucleating agent. Compared to EP600V, the onset of crystallisation is shifted slightly towards higher temperatures and the peak in general is slightly broadened and exhibits a pronounced shoulder. Nevertheless, despite being smaller than for EP600V, the difference between melting and crystallisation can be considered large enough for processing the powder in SLS. The DSC curves show only little effect of the cryogenic grinding on the thermal behaviour of the material. Only the shape of the crystallisation peak of Moplen EP548V changes as the peak maximum shifts from $128^{\circ} \mathrm{C}$ to about $123^{\circ} \mathrm{C}$. The peak onset of the crystallisation, however, remains unchanged. The addition of $0.1 \mathrm{wt} \%$ of Aerosil R8200 showed no effect on the thermal behaviour of the samples.

The particle size distribution of the raw powder is determined after cryogenic grinding. After the sieving step, roughly $90 \%$ of the particles are smaller than $100 \mu \mathrm{m}$. SEM images of the raw powders are presented in Figure 4. As expected, the particles have a rough and irregular, that is,
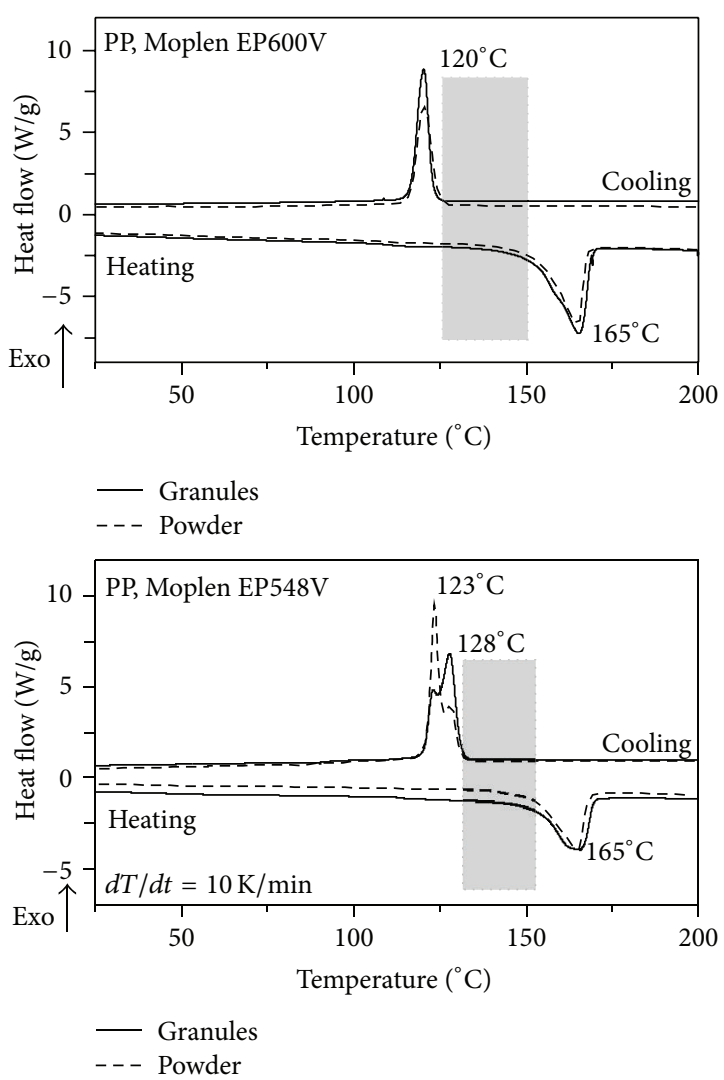

FIGURE 3: DSC traces (heating and cooling) of the investigated PP grades before and after cryogenic grinding. The grey boxes mark the respective windows of sinterability.

aspherical, shape due to the brittle fraction at the low process temperature. The raw ground powder also contains large particles and filament-like impurities, which are removed in the sieving step.

The results of the powder flow tests are shown in Figure 5. For the sieved raw powder, a measurement of the flow time at an opening of $d=25 \mathrm{~mm}$ yields a duration of about $8 \mathrm{~s}$ for the Moplen EP600V. With less than $6 \mathrm{~s}$, the flow time for the EP548V is much shorter, which can be attributed to the content of antistatic agent. Also, in contrast to the EP600V, a clean flow through the funnel is observed during the testing of the flow properties of EP548V with only little residue remaining in the test setup as electrostatic charging of the particles is prevented. For the smaller diameters of 15 and $10 \mathrm{~mm}$, respectively, no powder flow is detected for either material. Upon modification of EP600V through addition of $0.1 \mathrm{wt} \%$ Aerosil R8200, the pourability improves. A decrease in flow time (at $25 \mathrm{~mm}$ ) to just over $5 \mathrm{~s}$ is observed. Also, after the addition of the flow agent, the powder pours through the funnel at the smallest diameter $(10 \mathrm{~mm})$, which further shows improved flow behaviour. In accordance with these observations of the flow behaviour, the bulk density increases for both materials from about $0.33 \mathrm{~g} / \mathrm{cm}^{3}$ to well over $0.35 \mathrm{~g} / \mathrm{cm}^{3}$.

Figure 6 shows SEM images of particle surfaces of Moplen EP548V before and after dry particle coating with $0.1 \mathrm{wt} \%$ of Aerosil R8200. Comparing the two images, the adsorbed 


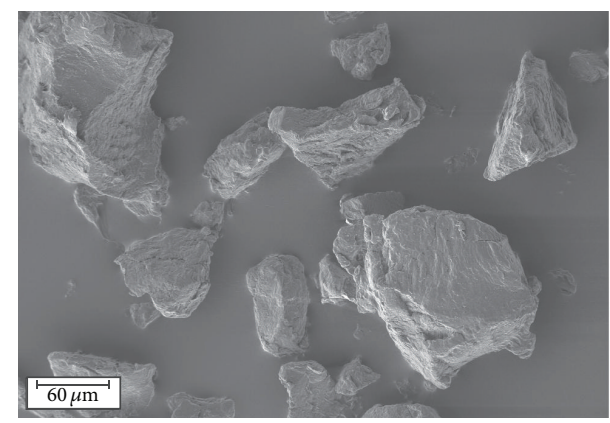

(a)

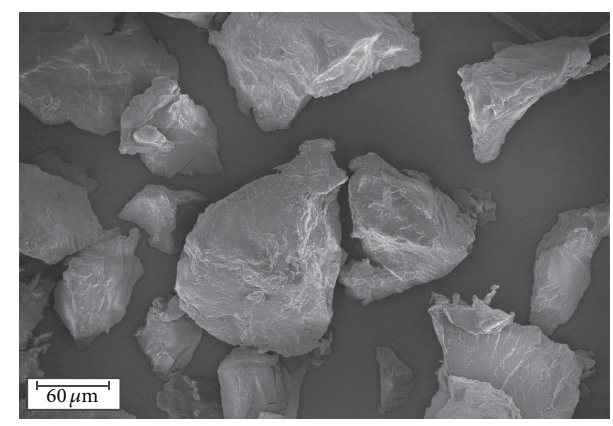

(b)

Figure 4: SEM images of cryogenically ground PP powders Moplen EP548V (a) and EP600V (b).
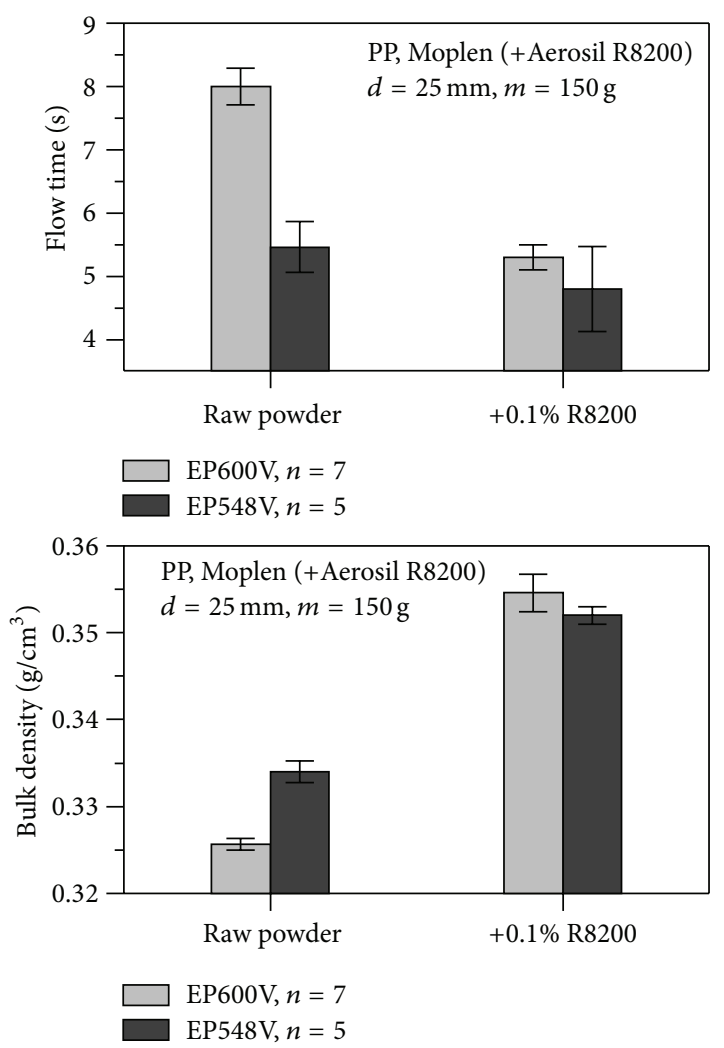

FIGURE 5: Flow time and bulk density of the cryogenically ground Moplen EP548V and EP600V before and after addition of $0.1 \mathrm{wt} \%$ of Aerosil R8200.

particles of the flow agent are clearly visible as bright spots on the surface. The pictures indicate that the small amount of the nanoscaled flow agent is evenly spread across the surface of the much larger polymer particle. Relating to the measurements of the flow behaviour, it can be noted that only a small fraction of the surface needs to be covered in order to greatly enhance the flow properties. As the particleparticle adhesion is reduced, the resistance to flow decreases and the funnel empties more quickly. Likewise, the powder can reach more dense packing within the bulk if they can pass by one another with less adhesive interaction retarding the
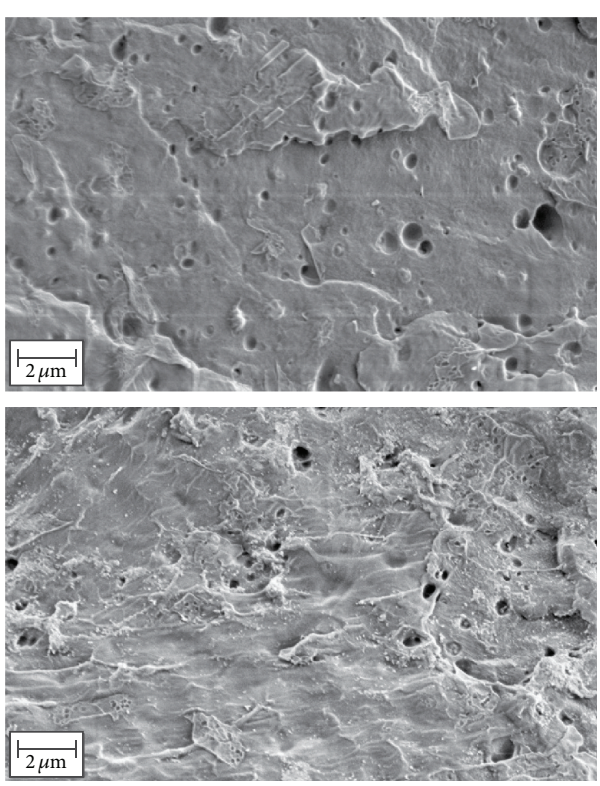

FIGURE 6: SEM images of the surface of the polymer particles (Moplen EP548V) before and after dry particle coating with $0.1 \mathrm{wt} \%$ of Aerosil R8200.

movement of the individual particles. Thus, the reduced flow time and increased bulk density can be attributed directly to the improved flow. Considering the findings by Ruppel [25], however, the flow behaviour depends not only on the size and number of the adsorbates on the surface of the polymer, but also on their three-dimensional shape, which unfortunately is not accessible from SEM. According to Ruppel, the shape is strongly determined by the conditions during the dry particle coating process, in particular the mixing time, which is not varied during this study.

3.2. Laser Sintering Studies. As already noted for the flowability tests, in comparison to the EP600V, the content of antistatic agent improves the behaviour of the EP548V powder. Generally, the powder handling is facilitated and during the SLS process less powder sticks to the coating mechanism due to electrostatic charging of the polymer particles. However, in accordance with observations by Goodridge 
et al. [8], both cryogenically ground polymer powders exhibit an unfavourable coating behaviour due to the insufficient flowability. Attempts to use the raw material for SLS without further modification lead to a failure of the process. Because the powder does not flow freely in front of the roller during the coating phase, there is a strong mechanical interaction between the powder and the melt pool of the previously exposed layer. This causes the unfinished parts to be pushed out of their original position within the part bed.

After the addition of $0.1 \mathrm{wt} \%$ of Aerosil R8200, however, the processing behaviour greatly improves. Only due to the increased flowability of the polymer powder is the manufacturing of parts possible and tensile bars can be produced with both PP powder materials. Notably, after the exposure, the surface of the resulting melt pools exhibits a plain and glossy surface, unseen for the processing of typical PA 12 materials. Also, the melt is completely transparent and the powder surface below the exposed volume is clearly visible. Figure 7 shows a photograph of test geometries within the part bed during the phase of geometry exposure. During the studies, the powders show good suitability for reuse, with flow properties and melting behaviour remaining nearly constant over the course of several processing cycles.

3.3. Part Characterisation. The manufactured test bars have a smooth surface. The contours are clear and the edges are formed properly. A difference between the different levels of energy density is hardly noticeable. The contours appear to be slightly sharper for the lower energy density. This could be explained by a higher intermediate temperature of the melt pool for the higher laser power and consequently surrounding powder particles attaching to the part's surface due to heat conduction and partial melting of the surrounding particles. The difference in the appearance, however, is very small. Figure 8 provides information on the accuracy of the parts manufactured with Moplen EP600V and EP548V, respectively. No scaling factors were applied upon the manufacturing of the parts. The parts show an overall tendency for oversize. The difference between the two materials and for different laser parameters is only marginal. It is important to note that the exposed geometry contracts upon cooling and crystallisation of the parts. Therefore, undersize would be a natural phenomenon, which in practice is usually compensated by the application of scaling factors on the respective $\mathrm{CAD}$ file $[36,37]$. The oversize of the parts can probably be explained by the end-of-vector effect [15] which can cause heat accumulations at the edges of the samples and thus partial melting of the surrounding powder particles.

The results from tensile tests on the laser sintered test specimens are summarised in Figure 9. Within the investigations, higher values for tensile strength and elongation at break were obtained for EP548V than for EP600V while for both materials a slight indication of increasing tensile strength is observed for a higher energy input. However, the test specimens manufactured with EP600V show that the total energy input appears not to be the only determining factor as the course is less clear in that case. The overall increase of the tensile strength with increasing energy input indicates that despite an almost similar outward appearance

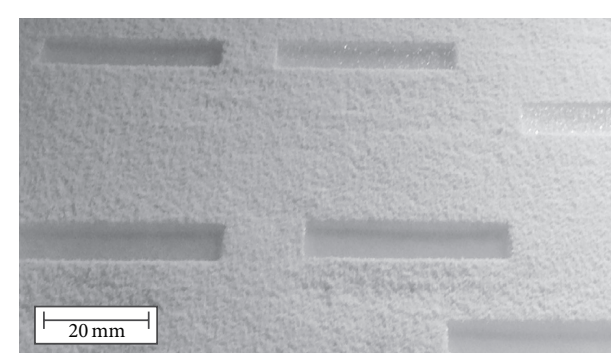

Figure 7: View into the process chamber while processing Moplen EP548V + 0.1 wt\% of Aerosil R8200.

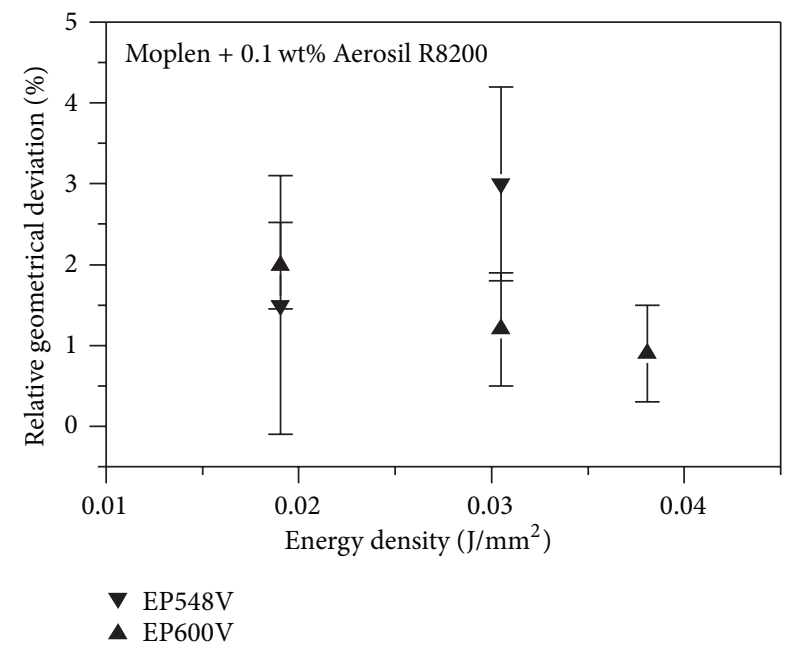

FIGURE 8: Relative geometrical deviation of laser sintered parts from CAD data.

and dimensional accuracy, the lower energy density causes the polymer particles to melt insufficiently. As a result, the parts' inner coherence is lower. A further increase of the laser power could possibly increase the degree of particle melt, as is noted for PA 12 [38]; however, dimensional accuracy tends to decrease at the same time. The results also indicate that with an increase of the energy input an improvement of the tensile strength and Young's modulus is achieved. However, at the same time, the elongation at break decreases slightly. While EP548V again yielded higher values for the elongation at break than EP600V, Young's modulus tends to be somewhat lower.

Throughout the parameter variation, the elongation at break remained fairly constant around $1 \%$. Higher values could not be reached during the investigations. This brittle behaviour is rather untypical for injection moulded PP parts. In the case of PA 12, the brittle behaviour is overall attributed to the higher porosity (typically 3 to $5 \%$ ) compared to injection moulded parts [21,39]. Figure 10 shows a thin-layer microscopic image of a laser sintered part manufactured from EP600V with an energy density of $0.04 \mathrm{~J} / \mathrm{mm}^{2}$. In the image, the lines of the individual layers are visible and a relatively high porosity is noted. Although no quantitative evaluation of the porosity can be derived from the microscopic images, the high porosity appears to be the reason for the brittle 

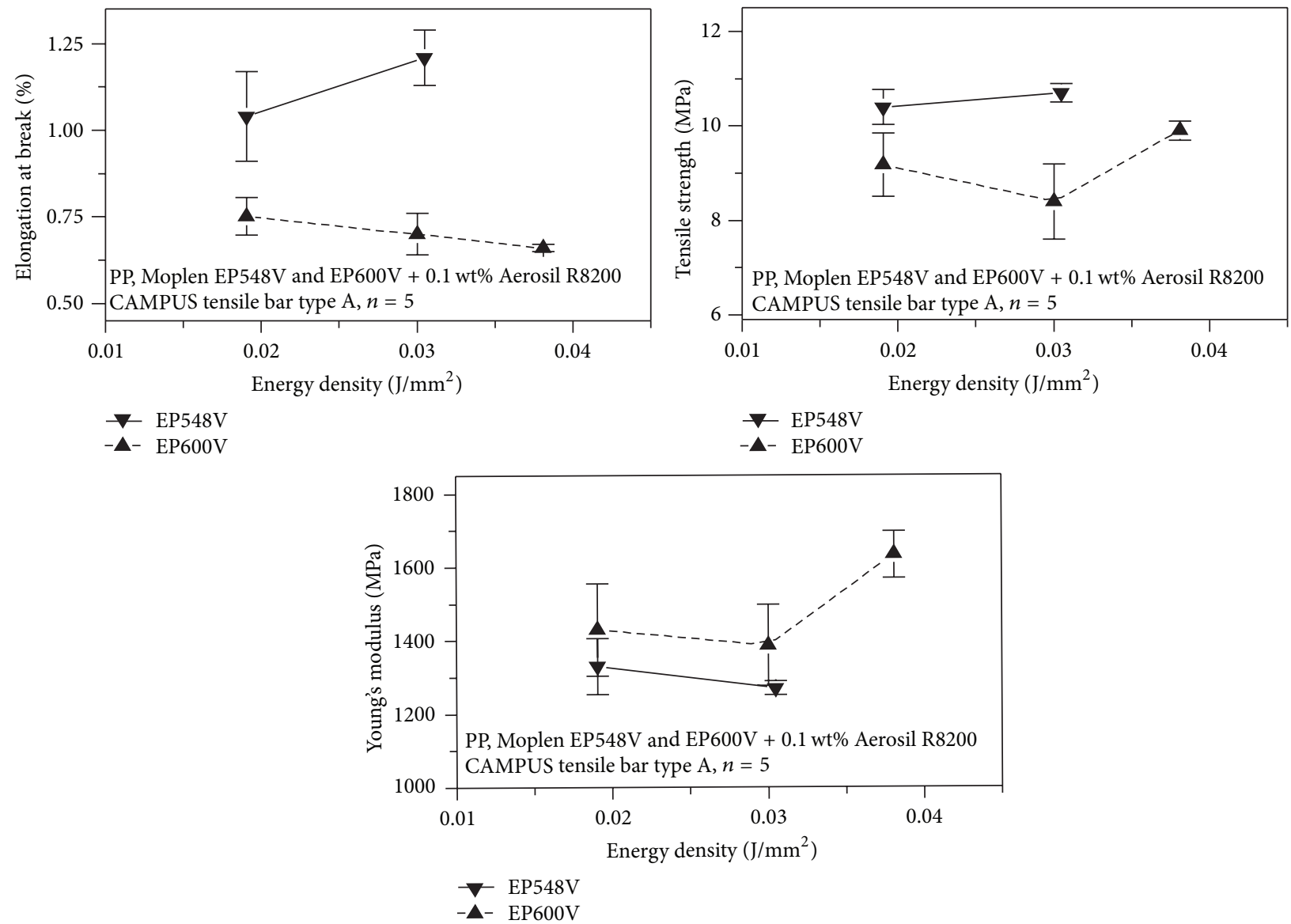

FIGURE 9: Mechanical properties of the laser sintered tensile bars as a function of the energy density during exposure.

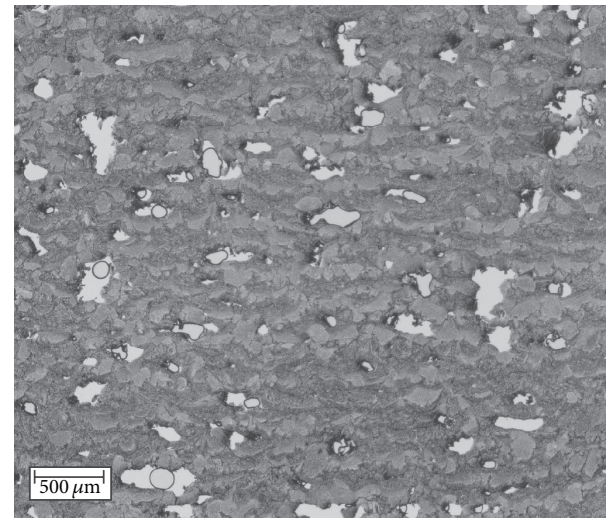

FIgURE 10: Thin-layer microscopic image of a laser sintered part manufactured with an energy density of $0.04 \mathrm{~J} / \mathrm{mm}^{2}$ from Moplen EP600V after addition of $0.1 \mathrm{wt} \%$ of Aerosil R8200.

behaviour as a high part porosity usually implies inferior mechanical properties. The image also suggests incomplete melting of the particles, which could also affect the part mechanics. A quantification of the content of unmolten particles in correlation with the process parameters could be the subject of future investigations.

\section{Conclusions}

Modifying thermoplastic polymer powders with flow agents via dry particle coating proves to be a potent method for improving the process behaviour in SLS. In contrast to assumptions published previously in [21], the addition of flow agents appears to be especially effective for cryogenically ground polymer powders, which inherently exhibit a rather poor flowability. While the good impact resistance of the PP grades selected for the present study is ultimately a desirable property for the resulting SLS parts, it proves to be problematic during the pulverisation of the granules via cryogenic grinding. The high toughness is assumed to be the reason for a relatively high mean particles size of the ground polymer powder in spite of the very low temperatures during grinding. Also, problems still arise considering the realisation of the favourable impact properties for the SLS parts. With values for the elongation at break around $1 \%$, there is still potential for improvement. In fact, the improvement of the rather brittle behaviour of laser sintered PP parts is one of the key topics of ongoing research. Current research approaches this problem through copolymerisation. In this way, values for the elongation at break as high as $200 \%$ have been achieved recently for a PP based material [21], however, at the cost of much lower Young's modulus and a substantially higher price. 
The results from the sintering studies reveal a range of stable processing parameters and show potential for possible further improvement of the part characteristics. While the content of antistatic agent shows a great improvement in general powder handling, no significant change in the coating behaviour during SLS can be determined while using a roller. The strength of this approach surely lies in less particles sticking to the coating system, which could prove especially strong when using a blade-based mechanism, as particle accumulations at the blade's edges due to electrostatic charging can cause severe problems for the SLS process. Using a roller, however, it does not reveal considerable differences for the process.

Lastly, the effect of the antistatic agent appears to be superimposed by the flow agent. Despite being initially quite different considering flowability and electrostatic charging, the two Moplen powders show a very similar behaviour after addition of the flow agent. Because the particles of the two materials are of similar density, the flow behaviour of the composite particles is apparently determined mainly by the surface properties. Although the addition of the flow agent increases electrostatic charging of the powder, it also greatly improves the flow behaviour of both investigated PP grades enabling them for use as cheap materials for SLS.

\section{Competing Interests}

The authors declare that they have no competing interests.

\section{Acknowledgments}

This work is funded by the Projektträger Jülich $\mathrm{GmbH}$. The authors express their gratitude towards BMW Group, Fraunhofer UMSICHT, and Sintermask GmbH for the collaboration within the Neue Werkstoffe in Bayern Project "Entwicklung Thermoplastischer Lasersinterwerkstoffe für den Technischen Einsatz." LyondellBasell Industries N.V. is greatly acknowledged for providing the granular polymer materials. The authors acknowledge support by Deutsche Forschungsgemeinschaft and Friedrich-Alexander-Universität ErlangenNürnberg (FAU) within the funding programme Open Access Publishing.

\section{References}

[1] R. D. Goodridge, M. L. Shofner, R. J. M. Hague et al., "Processing of a Polyamide-12/carbon nanofibre composite by laser sintering," Polymer Testing, vol. 30, no. 1, pp. 94-100, 2011.

[2] T. Wohlers and T. Caffrey, Wohlers Report 2014: 3D Printing and Additive Manufacturing State of the Industry, 2014.

[3] A. Wegner, Theorie über die Fortführung von Aufschmelzvorgängen als Grundvoraussetzung für eine robuste Prozessführung beim Laser-Sintern von Thermoplasten [M.S. thesis], University of Duisburg-Essen, Essen, Germany, 2015.

[4] VDI, Generative Fertigungsverfahren, Rapid-Technologien (Rapid Prototyping), VDI 3404, 2007.

[5] N. Hopkinson, R. J. M. Hague, and P. M. Dickens, Rapid Manufacturing-An Industrial Revolution for the Digital Age, John Wiley \& Sons, Chichester, UK, 2006.
[6] M. Launhardt, M. Drexler, and D. Drummer, "Rapid-manufacturing-process for elastomeric components," International Journal of Recent Contributions from Engineering, Science \& IT, vol. 3, no. 2, pp. 1-6, 2015.

[7] T. Wohlers, Wohlers Report 2009-Rapid Prototyping-State of the Industry, 2009.

[8] R. D. Goodridge, C. J. Tuck, and R. J. M. Hague, "Laser sintering of polyamides and other polymers," Progress in Materials Science, vol. 57, no. 2, pp. 229-267, 2012.

[9] T. Seul, Ansätze zur werkstoffoptimierung beim lasersintern durch charakterisierunng und modifizierung grenzflächenenergetischer phänomene [Ph.D. thesis], Technische Hoschule, Aachen, Germany, 2003.

[10] K. Wudy, D. Drummer, F. Kühnlein, and M. Drexler, "Influence of degradation behavior of polyamide 12 powders in laser sintering process on produced parts," in Proceedings of the pps29: The 29th International Conference of the Polymer Processing Society-Conference Papers, vol. 1593 of AIP Conference Proceedings, pp. 691-695, Nuremberg, Germany, July 2013.

[11] K. Wudy, D. Drummer, and M. Drexler, "Selective laser melting of polyamide 12: a holistic approach for modeling of the aging behaviour," in Proceedings of the 5th International Conference on Additive Technologies (iCAT '14), Vienna, Austria, 2014.

[12] A. Mazzoli, G. Moriconi, and M. G. Pauri, "Characterization of an aluminum-filled polyamide powder for applications in selective laser sintering," Materials \& Design, vol. 28, no. 3, pp. 993-1000, 2007.

[13] S. Negi, S. Dhiman, and R. K. Sharma, "Determining the effect of sintering conditions on mechanical properties of laser sintered glass filled polyamide parts using RSM," Measurement, vol. 68, pp. 205-218, 2015.

[14] S. R. Athreya, K. Kalaitzidou, and S. Das, "Processing and characterization of a carbon black-filled electrically conductive Nylon-12 nanocomposite produced by selective laser sintering," Materials Science and Engineering A, vol. 527, no. 10-11, pp. 26372642, 2010.

[15] U. Ajoku, N. Saleh, N. Hopkinson, R. Hague, and P. Erasenthiran, "Investigating mechanical anisotropy and end-of-vector effect in laser-sintered nylon parts," Proceedings of the Institution of Mechanical Engineers Part B: Journal of Engineering Manufacture, vol. 220, no. 7, pp. 1077-1086, 2006.

[16] T. Laumer, K. Wudy, M. Drexler et al., "Fundamental investigation of laser beam melting of polymers for additive manufacture," Journal of Laser Applications, vol. 26, no. 4, Article ID 042003, 2014.

[17] M. Zhao, D. Drummer, K. Wudy, and M. Drexler, "Untersuchung des schmelz- und sinterprozesses von polyamid 12 beim selektiven strahlschmelzen," in Proceedings of the RapidTech, Erfurt, Germany, June 2015.

[18] M. Drexler, K. Wudy, and D. Drummer, "Einfluss des pulverauftragsprozesses auf den selektiven strahlschmelzprozess thermoplastischer kunststoffe," in Proceedings of the Tagungsband/Digital Proceedings RapidTech, Erfurt, Germany, 2015.

[19] M. Drexler, M. Lexow, and D. Drummer, "Selective laser melting of polymer powder-part mechanics as function of exposure speed," Physics Procedia, vol. 78, pp. 328-336, 2015.

[20] K. Wudy, M. Drexler, and D. Drummer, "Selektives strahlschmelzen von polymer-blends: prozess-und werkstoffanforderungen," in Proceedings of the Tagungsband/Digital Proceedings RapidTech, Erfurt, Germany, 2015.

[21] M. Schmid, Selektives Lasersintern (SLS) Mit Kunststoffen, Carl Hanser, München, Germany, 1st edition, 2015. 
[22] D. Drummer, M. Drexler, and K. Wudy, "Density of laser molten polymer parts as function of powder coating process during additive manufacturing," Procedia Engineering, vol. 102, pp. 1908-1917, 2015.

[23] C. H. Clausen, D. J. Mickish, W. J. Nebe, and S. R. Vaidya, "Laser sinterable thermoplastic powder," US Patent 6110411, 2000.

[24] H. Chung and S. Das, "Functionally graded Nylon-11/silica nanocomposites produced by selective laser sintering," Materials Science and Engineering A, vol. 487, no. 1-2, pp. 251-257, 2008.

[25] J. Ruppel, Vergleich unterschiedlicher Messmethoden zur Beurteilung der Potenz nanostrukturierter Fließregulierungsmittel [M.S. thesis], Julius-Maximilians-Universität Würzburg, Würzburg, Germany, 2007.

[26] G. Huber and K.-E. Wirth, "Electrostatically supported surface coating of solid particles in liquid nitrogen for use in DryPowder-Inhalers," Powder Technology, vol. 134, no. 3, pp. 181192, 2003.

[27] M. P. Mullarney, L. E. Beach, R. N. Davé, B. A. Langdon, M. Polizzi, and D. O. Blackwood, "Applying dry powder coatings to pharmaceutical powders using a comil for improving powder flow and bulk density," Powder Technology, vol. 212, no. 3, pp. 397-402, 2011.

[28] J. Edenbaum, Plastics Additives and Modifiers Handbook, Van Norstrand Reinhold, New York, NY, USA, 1992.

[29] H. Zweifel, R. Maier, and M. Schiller, Plastics Additives Handbook, Carl Hanser, München, Germany, 6th edition, 2009.

[30] J. C. Nelson, Selective laser sintering: a definition for the process and an empirical sintering model [Ph.D. dissertation], University of Texas at Austin, Austin, Tex, USA, 1993.

[31] L. Fiedler, L. O. Garcia Correa, H.-J. Radusch, A. Wutzler, and J. Gerken, "Evaluation of polypropylene powder grades in consideration of the laser sintering processability," Journal of Plastics Technology, vol. 4, no. 3, p. 14, 2007.

[32] Y. Shi, Z. Li, H. Sun, S. Huang, and F. Zeng, "Effect of the properties of the polymer materials on the quality of selective laser sintering parts," Proceedings of the Institution of Mechanical Engineers, Part L, vol. 218, no. 3, pp. 247-252, 2004.

[33] C. Blümel, Charakterisierung der Trockenen Beschichtung zur Herstellung von maßgeschneiderten Kompositpartikeln [M.S. thesis], Friedrich-Alexander-Universität Erlangen-Nürnberg, Erlangen, Germany, 2015.

[34] A. Wegner and G. Witt, "Correlation of process parameters and part properties in laser sintering using response surface modeling," Physics Procedia, vol. 39, pp. 480-489, 2012.

[35] R. D. Goodridge, R. J. M. Hague, and C. J. Tuck, "An empirical study into laser sintering of ultra-high molecular weight polyethylene (UHMWPE)," Journal of Materials Processing Technology, vol. 210, no. 1, pp. 72-80, 2010.

[36] D. T. Pham, S. Dimov, and F. Lacan, "Selective laser sintering: applications and technological capabilities," Proceedings of the Institution of Mechanical Engineers, Part B: Journal of Engineering Manufacture, vol. 213, no. 5, pp. 435-449, 1999.

[37] J. Shen, J. Steinberger, J. Göpfert et al., "Inhomogeneous shrinkage of polymer materials in selective laser sintering," in Proceedings of the Solid Freeform Fabrication (SFF'00), pp. 298305, University of Texas, Austin, Tex, USA, 2000.

[38] C. Majewski, H. Zarringhalam, and N. Hopkinson, "Effect of the degree of particle melt on mechanical properties in selective laser-sintered Nylon-12 parts," Proceedings of the Institution of Mechanical Engineers, Part B: Journal of Engineering Manufacture, vol. 222, no. 9, pp. 1055-1064, 2008.
[39] S. Dupin, O. Lame, C. Barrès, and J.-Y. Charmeau, "Microstructural origin of physical and mechanical properties of polyamide 12 processed by laser sintering," European Polymer Journal, vol. 48, no. 9, pp. 1611-1621, 2012. 

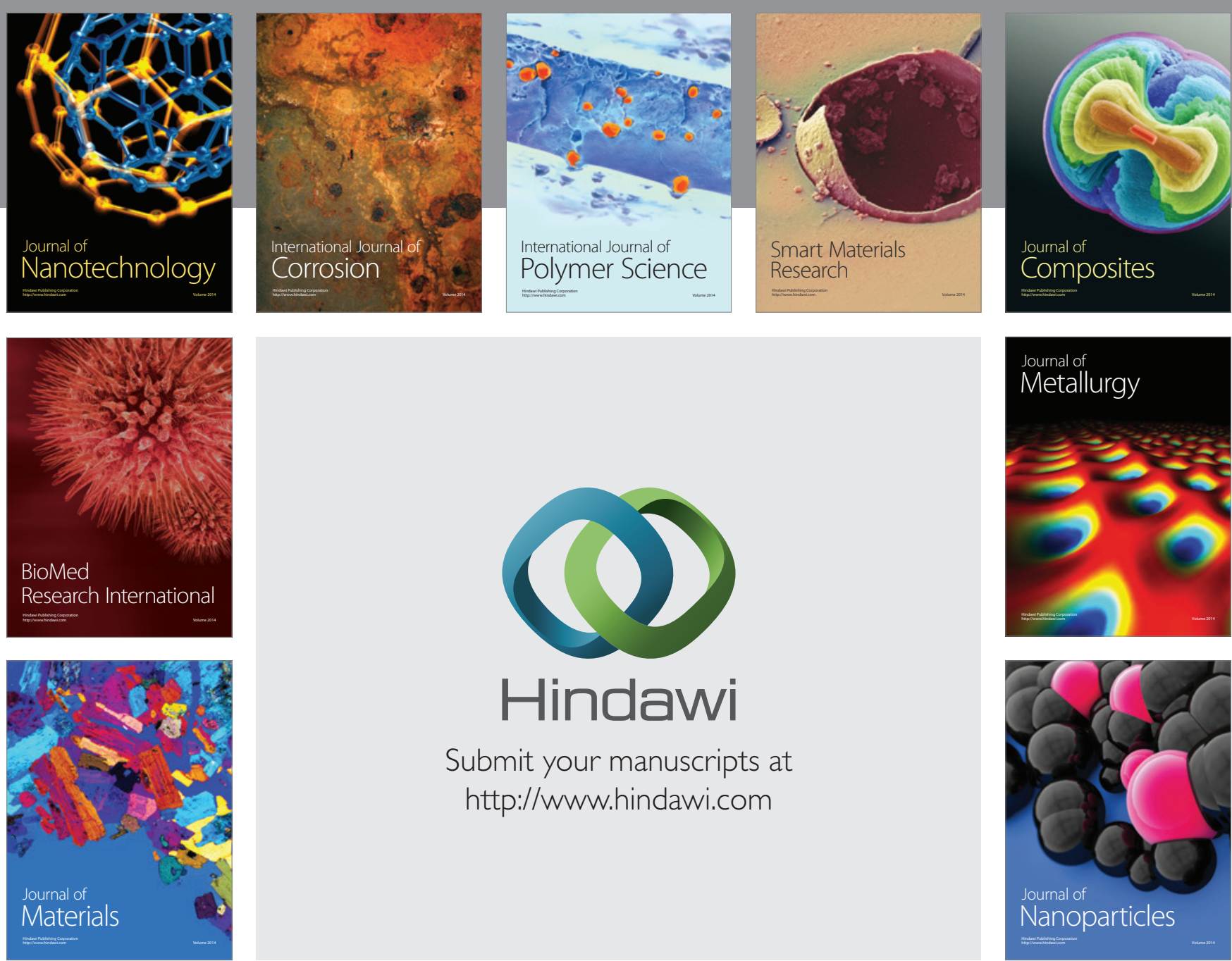

\section{Hindawi}

Submit your manuscripts at

http://www.hindawi.com

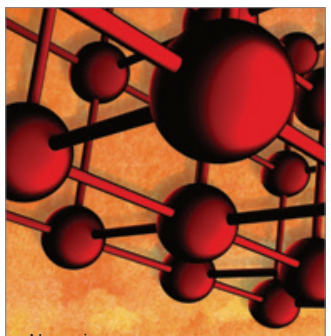

Materials Science and Engineering
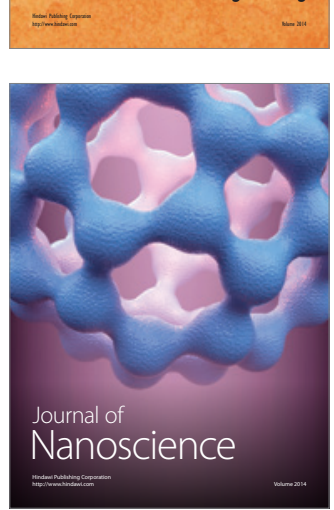
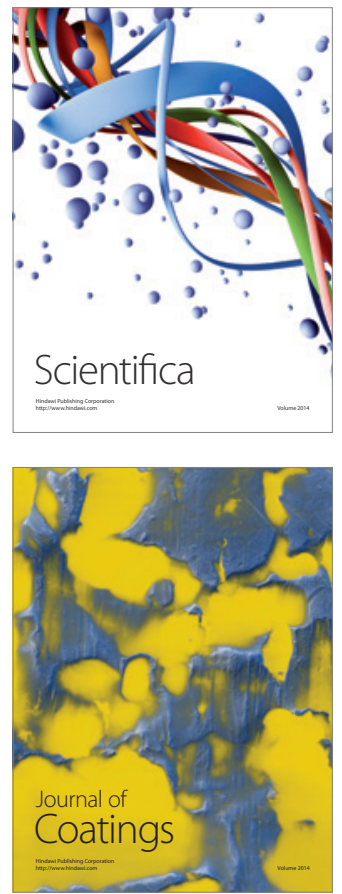
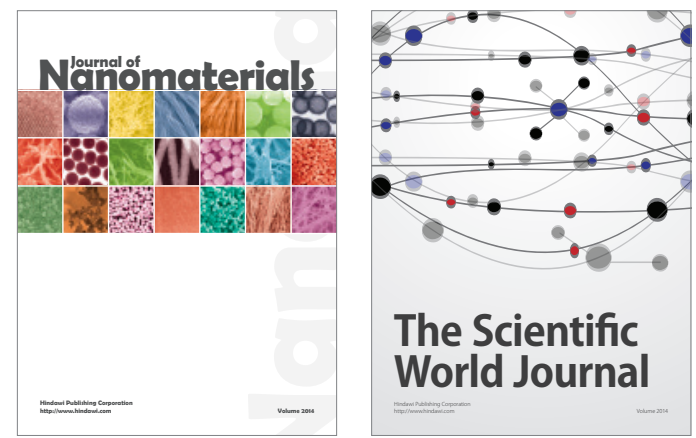

The Scientific World Journal
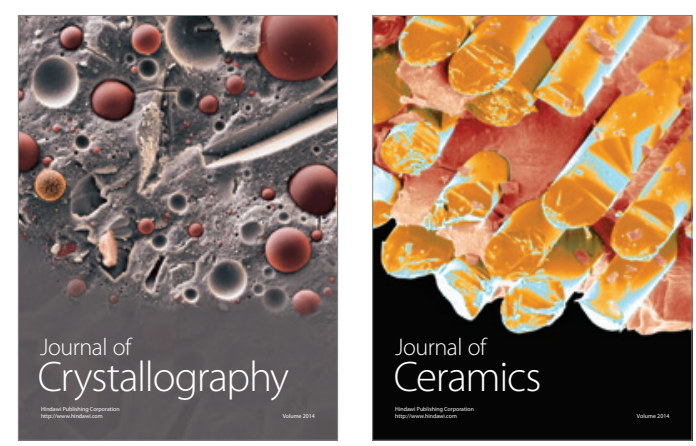
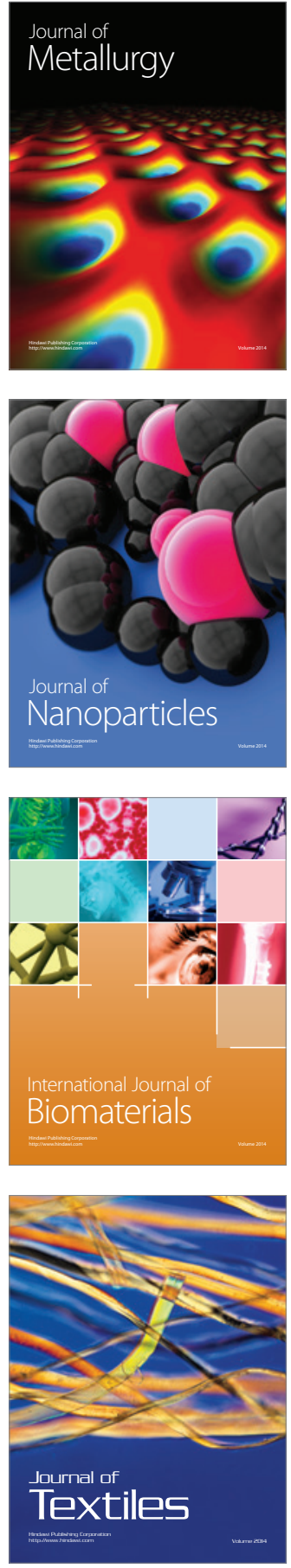